\title{
Effect of a Transducer Horizontality Default on Lake Fish Stock Assessment
}

\author{
Blanluet Arthur ${ }^{1,{ }^{*}}$, Goulon Chloe ${ }^{1}$, Lebourges-Dhaussy Anne ${ }^{2}$, Eymar-Dauphin Pauline ${ }^{1}$, \\ Guillard Jean ${ }^{1}$
}

${ }^{1}$ CARRTEL, INRAE, Univ. Savoie Mont Blanc, 74200, Thonon-les-Bains, France

2 LEMAR, IRD, UBO, CNRS, Ifremer, 29280, Plouzane, France

* Corresponding author : Arthur Blanluet, email address : $\underline{\text { arthur.blanluet@inrae.fr }}$

\begin{abstract}
:
reshwater hydroacoustic surveys are frequently performed with small research boats. Thus, the transducer, usually fixed on a pole on the side of the boat, could be misaligned with the horizontal axis (i.e., the lake surface). Given that fish acoustic responses are strongly directional, the transducer angle could induce attenuation of their backscattering strengths. To test the influence of a small shift of the transducer orientation, we compared hydroacoustics estimates from two sampling nights on the Lake Annecy: the first one being a transducer angle of $1.5 \circ$ with the horizontal and the second one being strictly horizontal. We showed that the effect of such an angle is negligible over the sampling variability on the TS distribution of the fish population and the biomass assessment. We conclude that a small shift in the transducer horizontality $(\leq 1.5 \circ)$ will not degrade the quality of the acoustic data.
\end{abstract}

Keywords : Fisheries acoustics, Freshwater, Transducer miss-alignment 


\section{Introduction}

Hydro-acoustics has become a requisite method to assess fish populations in lakes and is on the way of standardization [1, 2, 3]. It is a routine method in many European lakes [4, 5, 6].

Surveys are most of the time performed using small research boats $(<8 \mathrm{~m})$, with non-permanent acoustic equipment; the transducer being generally fixed to a pole at the boat side. These temporary installations can lead to some issues such as noises due to vibration or turbulence near the engine, but also a faulty installation of the transducer (incorrect setting/mounting) or variation of the boat angle due to movements of people on the boat and inadequate weight distribution. In vertical beaming, the transducer face must be oriented parallel to the lake surface. However, these issues could hinder this prerequisite to be filled.

Fish backscattering is highly dependent on fish orientation, over all other factors, such as sizes or species [7, 8]. In horizontal beaming, the fish orientations could have a dramatic impact on fish size estimations, and then on biomass assessments [9]. In vertical beaming, a transducer misalignment with the surface should have an impact on the incident angle of the fish, and then lowering the resulting backscattering [8]. To our knowledge, no publication has directly studied the effect of a transducer misalignment in situ.

In this study, we investigate the effect of transducer misalignment by a few degrees with the horizontal on fish stock assessment using two sampling nights performed at a one-day interval on the Lake Annecy (France). The first night of sampling was characterized by a small transducer misalignment.

We analyzed the impact of this misalignment on fish Target Strength (TS, dB,[10]), the corresponding modelled fish size using Love' equations [11] and on the fish biomass estimate at the whole lake scale. This issue is very common in lake fish stock assessment, 
and the conclusions of this study will be of great help to the freshwater fisheries acoustic community.

\section{Materials and Methods}

\subsection{Sampling}

This study is based on opportunistic data acquired during the annual monitoring fishstock assessment (OLA, Observatory of LAkes, [12) and a frequency comparison study [3] on the Lake Annecy. Due to inappropriate installation, the transducer presented a misalignment during the first sampling night, corrected for the second sampling night.

The first night of acquisition (night 1, 13/09/2016) was performed through parallel transects, when the second night (night 2, 14/09/2016) was performed through "Zig-zag" transects (Figure 1). These two types of sampling strategy give similar fish size distributions and biomass estimates [13]. The two nights presented similar weather conditions.

Detailed sampling protocols have been described previously in [3]. In the present publication, we focus on the $70 \mathrm{kHz}$ frequency, our referenced frequency in fish studies [14, 15, 16]. The echo-sounder was a Simrad EK60 with a split-beam transducer of 7 degree opening at $-3 \mathrm{~dB}$. The sounder ping interval varied from 0.15 to $0.3 \mathrm{~s}$. The pulse duration was set to $0.256 \mathrm{~ms}$ [17] with a transmitting power of $100 \mathrm{~W}$. The echo sounder was previously calibrated in the Ifremer tank at Brest (France), and again in situ prior to the survey, following the standard protocol [18, 19], and the manufacturer's manual. The transducer was mounted on a pole fixed on the side of the boat, at $0.7 \mathrm{~m}$ deep. The boat was sailing at approximately $8 \mathrm{~km} \cdot \mathrm{h}^{-1}$. 


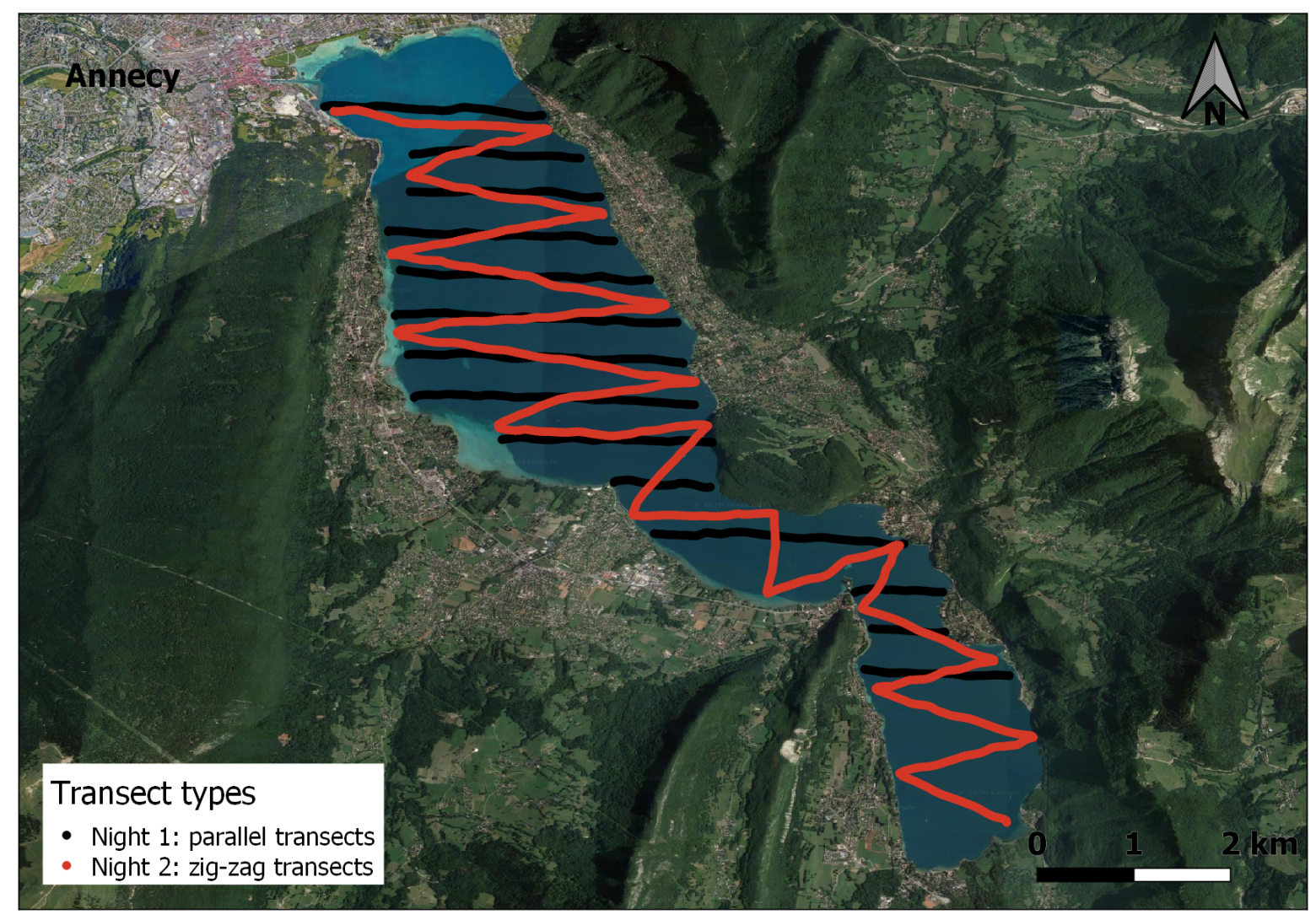

Figure 1: Survey tracks on the Lake Annecy (France) for night $1(13 / 09 / 2019)$ and night $2(14 / 09 / 2019)$

\subsection{Data processing}

Data were processed with SONAR 5 [20]. The TS threshold was set to $-60 \mathrm{~dB}$ and the Volume backscattering Strength $\left(S_{v}, d B\right.$ re $1 m^{-1}$, [10]) threshold to $-66 \mathrm{~dB}$ according to [21]. The SONAR 5 Single Echo Detection (SED) algorithm was set with an echo length ratio between 0.8 and 1.3, a maximum gain compensation of $3 \mathrm{~dB}$ (one way), and a sampling angle standard deviation of 0.3 degrees [3]. The Elementary Sampling Distance Unit (ESDU) was set to $250 \mathrm{~m}$ for the Area backscattering Strength $\left(S_{A}, m^{2} . h a^{-1}\right.$, [10, 20]) computation. The minimal number of pings for tracking was set to 2 above 13 $\mathrm{m}$ depth and 3 below this depth.

The methodology to assess fish populations in French alpine lakes is based on European standard [1, 2] and is described in detail elsewhere [3]. 
After echograms cleaning (noise, bubbles, plankton layers) using SONAR 5 tools, the echograms were split into three layers processed separately according to previous studies [22]. This splitting was based on the thermocline depth (13 m, Figure 2), and on the knowledge from experimental fishing [22] of a shift in the fish composition at around 35 $\mathrm{m}$ deep. The layer above the thermocline $(2$ to $13 \mathrm{~m})$ is mainly composed of Young-ofthe-Year perch (Perca fluviatilis) and roach (Rutilus rutilus) [15]. The layers below the thermocline are mainly composed of Salmonidae [23, 24]: whitefish (Coregonus lavaretus) for the second layer (13 to $35 \mathrm{~m}$ ) and a mix of European whitefish and Arctic charr (Salvelinus alpinus, approximately $90 \%$ whitefish and 10\% Arctic charr, [22]) for the third layer (35 $\mathrm{m}$ to the lake bed, around $70 \mathrm{~m})$.

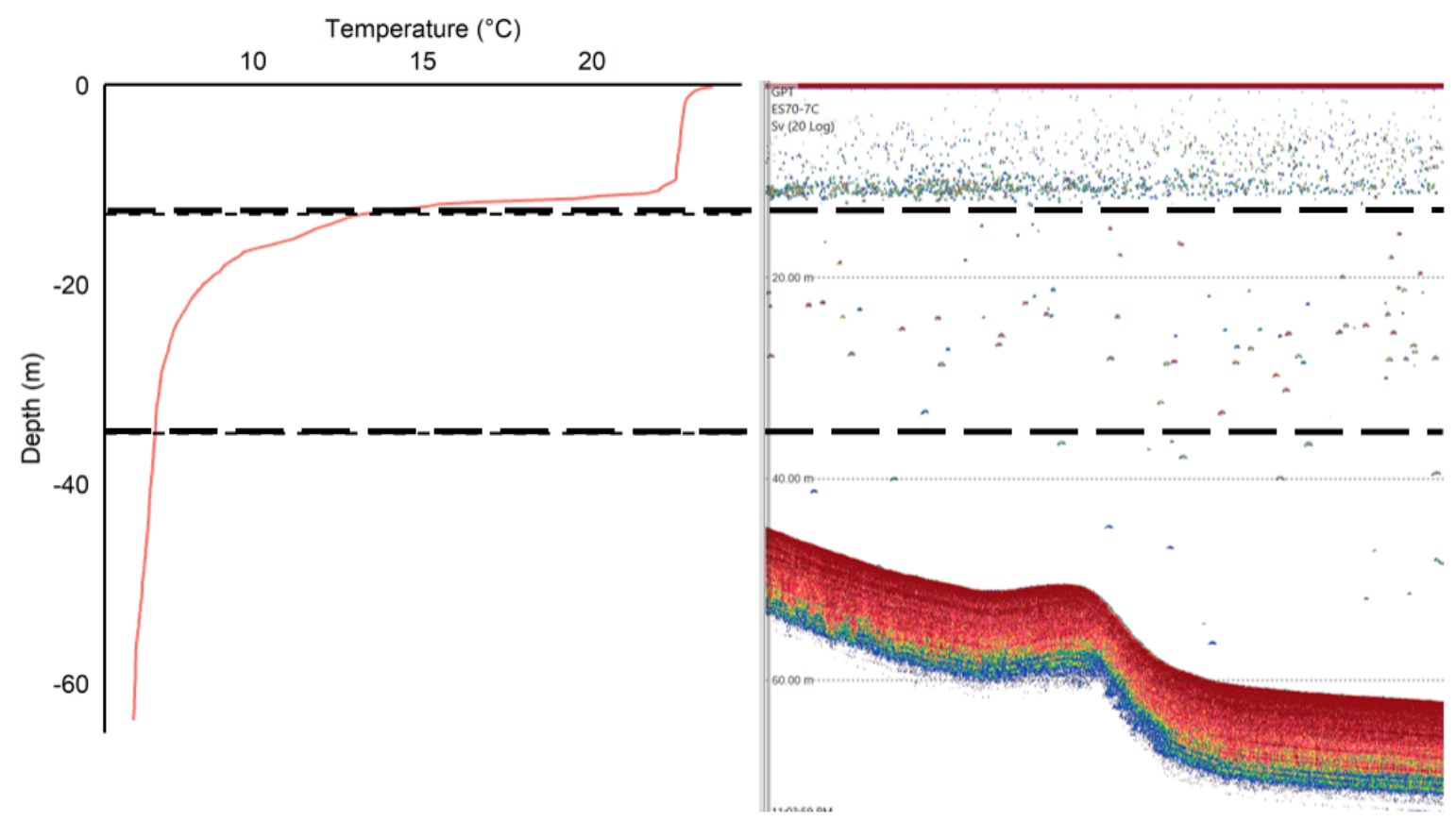

Figure 2: Left side - temperature profile acquired on 13/09/2019 in the Lake Annecy. Right side - echogram acquired on 14/09/2019, the dashed lines show the separation between the layers. Data from OLA, Observatory of LAkes (http://www6.inra.fr/soereola CSOERE OLA-IS.

For each layer, we extracted a mean TS (calculated in the linear domain) and a mean $S_{A}$ by ESDU all over the lake. The fish mean size, weight, density and then biomass were calculated using the formulae presented in detail in [3] and based on [25, 11] equations. 


\subsection{Angle determination}

As no direct measurement of the transducer angle has been performed during the first sampling night, so we had to estimate the transducer angle offset between the two nights through the fish orientation in the TS tracking after data processing.

The fish orientation has two angles components, the "tilt" angle, and the "swim" angle [26]. The tilt angle is defined by "the angle between the long axis of the fish and the incident wave front" [27], the swimming angle being defined by the fish swim direction on the vertical axis. These two angles are not necessarily equivalent. During echo-tracking, the SONAR 5 calculates the swimming angle, or more specifically, the mean "aspect angle" (or "pitch angle" [28]). The aspect angle is defined by the fish angle between the tracked ping $i$ and $i+1$ on the vertical axis [20].

$$
\left.{\text { Aspect } \text { angle }_{i}=\arctan }_{(} \frac{d z_{i}}{\sqrt{d x_{i}^{2}+d y_{i}^{2}}}\right)
$$

With $d z_{i}, d x_{i}$ and $d y_{i}$ the target displacement between the ping $i$ and the ping $i+1$, in each dimension [20, 28].

In practice, for a vertically oriented echo-sounder, the aspect angle, the tilt angle and the swimming angle are similar for a given fish [26].

When the transducer is not perfectly horizontal to the surface, the tilt angle will be a combination of the natural fish swim angle and the transducer angle. This angle divergence can be easily notable on echograms on deep fish ( > $20 \mathrm{~m}$, figure 3 (a) and (b)). To calculate the effect of the transducer angle on fish tilt angle, we measured the mean offset of aspect angle between night 1 and night 2 on each layer.

The shift in the distribution of the aspect angle between night 1 and night 2 can be observed in Figure 4. The transducer angle with the horizontal during night 1 have been estimated as $1.5^{\circ}[ \pm 0.13]$ (with $91.60^{\circ}[ \pm 0.06]$ and $90.13^{\circ}[ \pm 0.12]$, as the night 1 and night 
a) Night 1

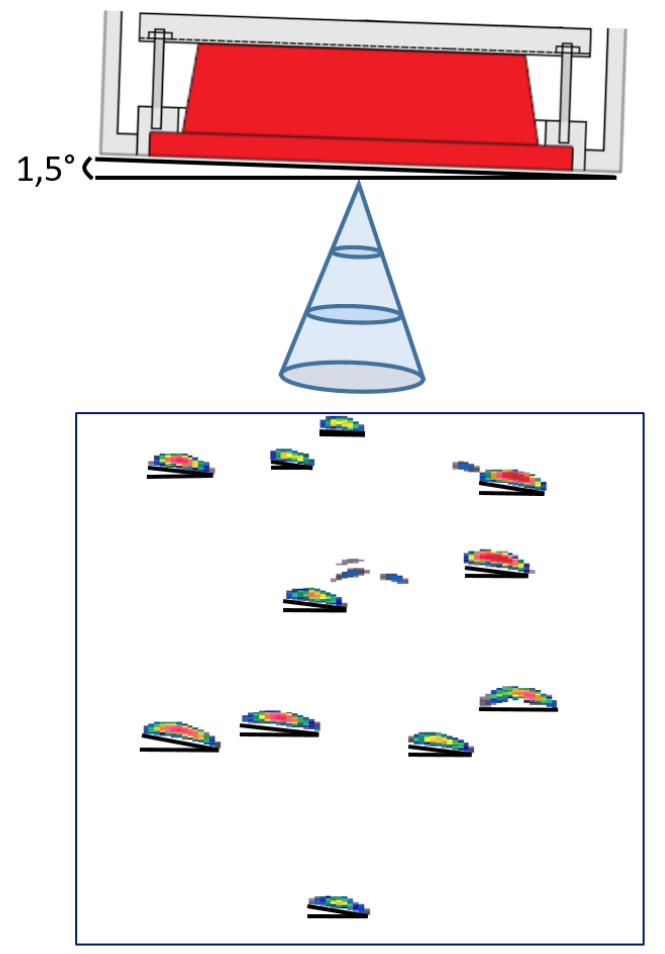

b) Night 2

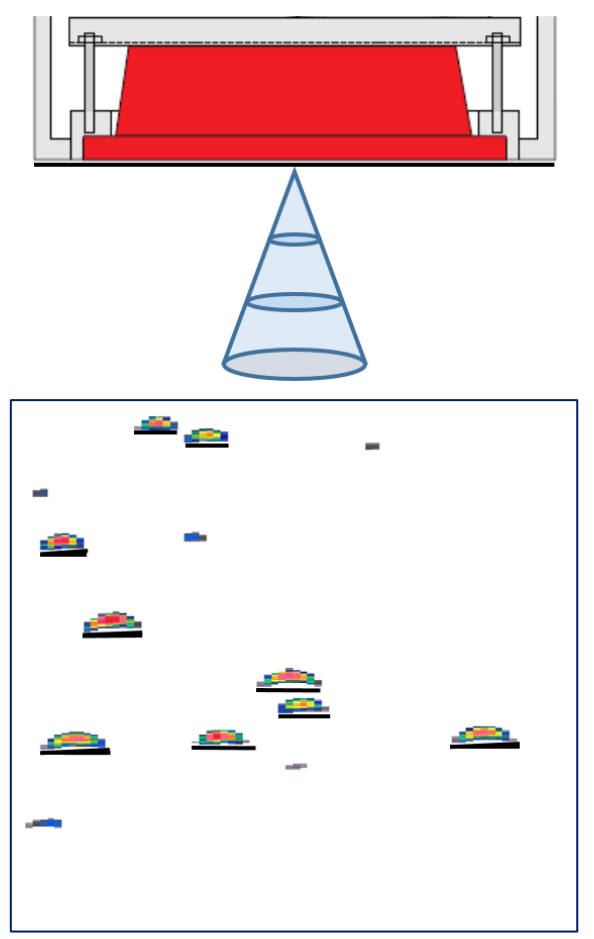

Figure 3: Transducer orientation mismatch between night 1 and night 2 and influence on fish echoes.

2 mean aspect angles for all layers, respectively). This value was relatively stable across layers, but with a higher value and variability for the $2-13 \mathrm{~m}$ layer $1.6^{\circ}[ \pm 0.33]$ than for the two deeper $\left(1.3^{\circ}[ \pm 0.024]\right.$ for the $13-35 \mathrm{~m}$ and $1.3^{\circ}[ \pm 0.030]$ for the $35-70 \mathrm{~m}$ layer $)$. The aspect angles of fish of the shallower layer were less accurate compared to the deeper layers, as there are fewer pings per track for each fish. If there was some variability on the fish tilt angle (Figures 3 and 4), it was very low and values for each sampling night were tightened around the principal mode.

\subsection{Influence on biomass assessments}

Because the backscattering of fish highly depends on its orientation [7] and the maximum backscattering is generally obtained for a normal incident angle with the swimbladder axis [29], we hypothesized that the mean TS should be slightly lower for the first night. 


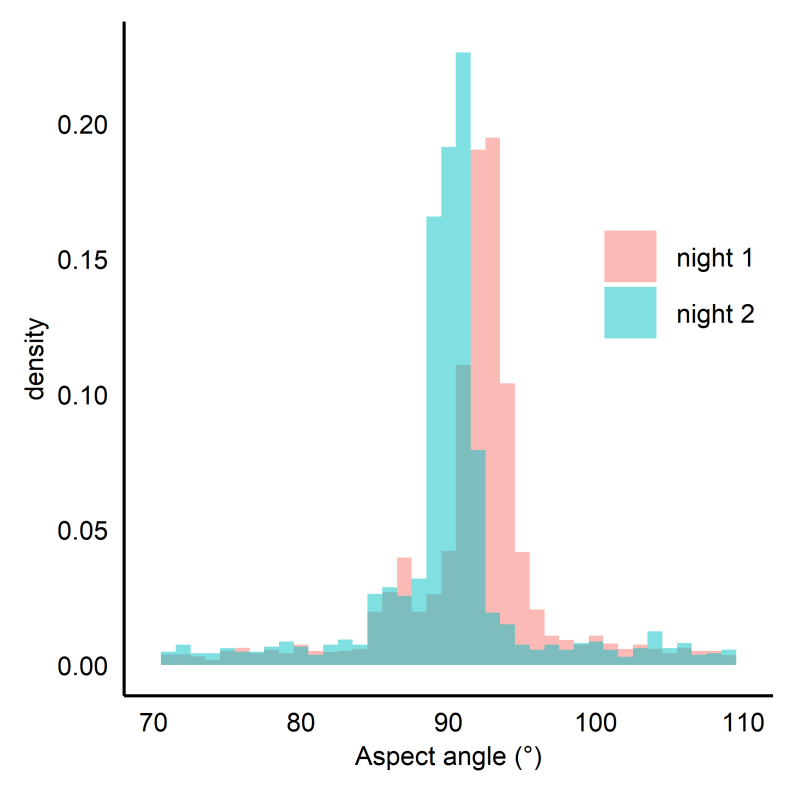

Figure 4: Aspect angle histograms of night 1 and night 2 for the three layers.

Thus, to investigate the possible transducer angle effect on stock assessment, we compared the two sampling nights TS distributions by layers using Kolmogorov-Smirnov tests (package "stat", R, [30]), and we investigated their influence on biomass evaluation. We estimated a confidence interval by bootstrapping (package "boot", R, [30]) around the mean TS, size, $S_{A}$ and estimated biomass. 


\section{Results}

During night 1, 1571 tracked fish echoes were recorded for $31.4 \mathrm{~km}$ of acquisition. During night 2, 1260 tracked fish echoes were recorded for $28.7 \mathrm{~km}$ of acquisition. The fish echoes number ratio between the two sampling nights is relatively stable through the layers (1036/832 for layer 1, 255/198 for layer 2 and 280/230 for layer 3).

The TS distributions are shown in Figure 5 for each layer and sampling nights. The mean TS, calculated lengths, $S_{A}$ and biomass are shown Table 1. The calculated mean length values are consistent with the net samplings [31].

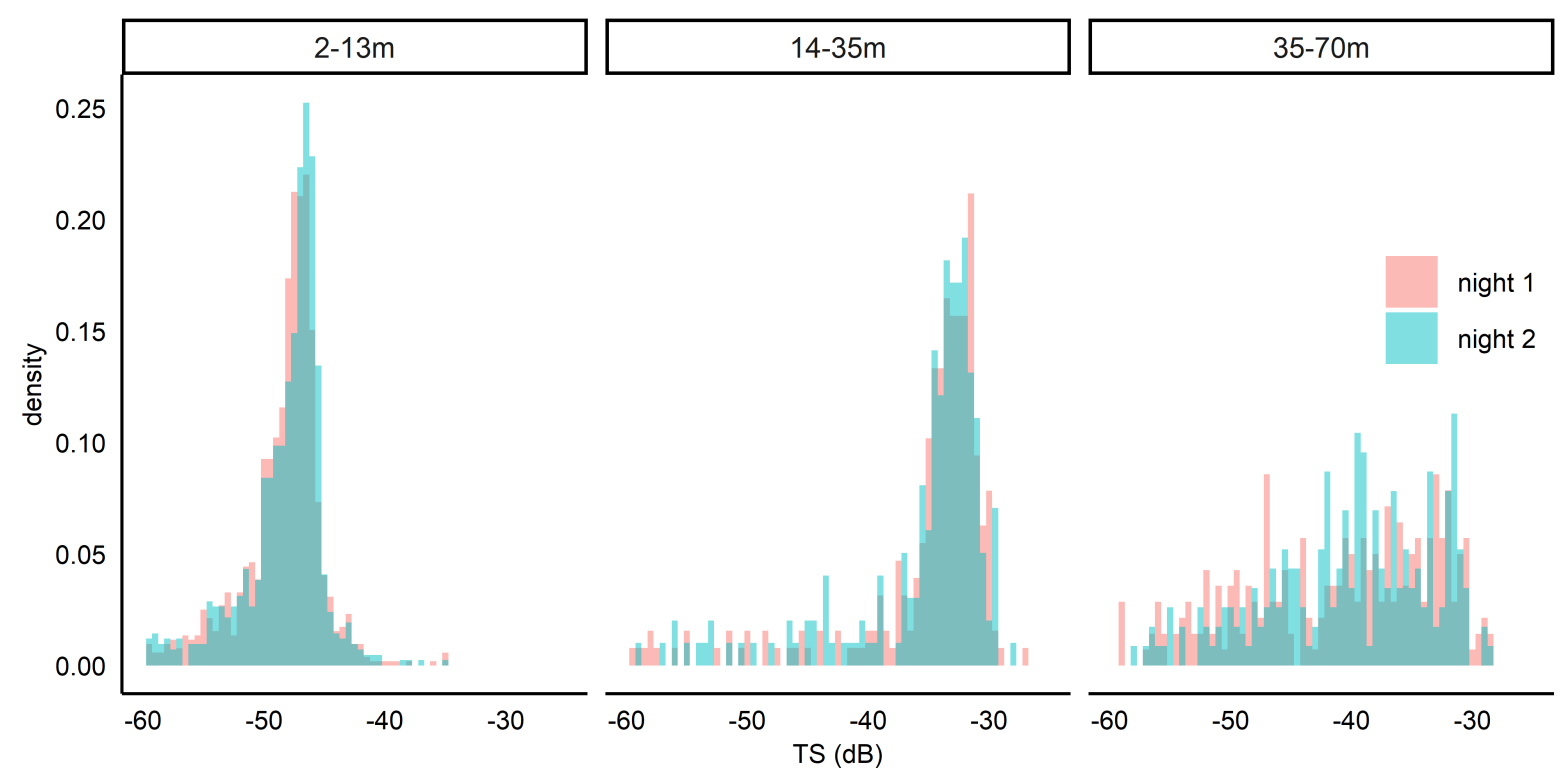

Figure 5: TS (dB) histograms of the three layers ((a) 2-13 m, (b) 13-35 m, (c) 35-70 m) for night 1 and night 2

Estimates for the surface layer $(2-13 \mathrm{~m})$ : The TS distributions of the surface layer presented similar shapes for night 1 and night 2 (Figure 5 (a)), with a $0.8 \mathrm{~dB}$ shift for the mode (Figure 5 (a)), $-47.6 \mathrm{~dB}$ for night 1 and $-46.8 \mathrm{~dB}$ for night 2. The two mean TS values were similar (less than $0.1 \mathrm{~dB}$ difference between the two values, Table 1). Nevertheless, the two distributions were considered different by a Kolmogorov-Smirnov test $(\mathrm{p}$-value $=0.00088)$.

Despite this statistical difference for the TS distributions, the two nights bootstrapped confidence limits for mean TS, estimated mean length, $S_{A}$ and biomass largely overlapped, 
Table 1: Mean TS $(d B)$, calculated length $(\mathrm{cm}), S_{A}\left(\mathrm{~m}^{2} \cdot h \mathrm{a}^{-1}\right)$, and biomass $\left(k g . h \mathrm{a}^{-1}\right)$ for the three layers $(2-13 \mathrm{~m}, 13-35 \mathrm{~m}, 35-70 \mathrm{~m})$ for the two sampling nights. $95 \%$ confidence interval are presented between brackets.

\begin{tabular}{c|ccccc}
\hline \hline Depth layer & Night & Mean TS $(d B)$ & mean length $(\mathrm{cm})$ & mean $S_{A}\left(\mathrm{~m}^{2} . h a^{-1}\right)$ & biomass $\left(\mathrm{kg} \cdot h \mathrm{~h}^{-1}\right)$ \\
\hline $2-13 \mathrm{~m}$ & 1 & $-47.2[-47.4,-46.8]$ & $7.3[7.1,7.6]$ & $1.11[0.93,1.33]$ & $17.8[14.5,22.1]$ \\
$2-13 \mathrm{~m}$ & 2 & $-47.1[-47.3,-46.8]$ & $7.4[7.2,7.7]$ & $1.10[0.96,1.27]$ & $18.0[15.1,20.8]$ \\
& & & & & \\
$13-35 \mathrm{~m}$ & 1 & $-33.3[-33.6,-33.0]$ & $38.9[37.4,40.5]$ & $1.08[0.96,1.23]$ & $107.5[89.0,125.1]$ \\
$13-35 \mathrm{~m}$ & 2 & $-33.4[-33.6,-33.0]$ & $38.2[36.5,40.0]$ & $0.96[0.85,1.07]$ & $93.7[75.7,111.7]$ \\
& & & & & \\
$35-70 \mathrm{~m}$ & 1 & $-36.1[-36.7,-35.5]$ & $27.7[25.7,29.8]$ & $0.11[0.09,0.13]$ & $7.4[5.2,9.6]$ \\
$35-70 \mathrm{~m}$ & 2 & $-36.4[-37.0,-35.7]$ & $26.9[24.8,29.2]$ & $0.08[0.07,0.11]$ & $5.5[3.8,7.2]$ \\
\hline \hline
\end{tabular}

and these values could be considered similar.

Estimates for the mid layer $(\mathbf{1 3 - 3 5} \mathbf{~ m})$ : The TS distribution for the mid-layer also presented similar shapes for night 1 and night 2 (Figure 5(b)), with a $2 \mathrm{~dB}$ shift for the mode (-31.6 dB for night 1 and $-33.6 \mathrm{~dB}$ for night 2$)$. However there was no such shift noticed for the mean TS values (Table 1), and the two distributions were not considered significantly different by the Kolmogorov-Smirnov test $(\mathrm{p}$-value $=0.7216)$.

The mean TS and mean estimated length value were between the two sampling nights (Table 1) as their bootstrapped confidence intervals largely overlapped. However, there was a notable difference between night 1 and night 2 in the mean $S_{A}$, their bootstrapped confidence interval did not overlap on an important part of the distribution. This implies a difference in the estimated biomass : $+15 \%$ between night 1 and night 2 .

Estimates for the deep layer $(>\mathbf{3 5} \mathbf{~ m})$ : In the deeper layer, TS distributions did not present any mode (Figure 5(c)); the two mean TS values were close, with a difference of $0.3 \mathrm{~dB}$ (Table 1), and the Kolmogorov-Smirnov test did not find a significant difference between the two distributions $(\mathrm{p}$-value $=0.1364)$.

As for the mid layer, there was a notable shift in bootstrapped confidence intervals for the mean $S_{A}$. This implies a significant difference in the estimated biomass: $+35 \%$ between night 1 and night 2 . 


\section{Discussions}

The transducer angle difference was easily seen when comparing the tracked TS fish tilt angle distributions between night 1 (with a transducer misalignment) and night 2 (without). However, this angle had no impact on the TS mean values for the three layers. On the TS distributions, the surface layer $(2-13 \mathrm{~m})$ showed a significant $0.8 \mathrm{~dB}$ shift in the TS mode between night 1 and night 2 that could be attributed to the transducer angle effect. No significant differences in TS distribution have been shown between the two nights for the two deeper layers. This difference between layers could be explained by the high number of fish sampled in the upper layer compare to the two deeper layers. A small variation of the TS distribution would be perceptible in a large sample, when it is hidden by the high variability of smaller samples. However, this difference could also be potentially attributed to the natural orientation of the swimbladder in the fish body, which is not generally completely parallel to the fish axis [32], and is highly dependent on the fish species [32, 33]. Thus, perch presents a swimbladder tilt angle of $8-10^{\circ}$ [34] when salmonids like whitefish or salmon (Salmo salar) present a lesser tilt angle of $2-3^{\circ}[35]$. We can hypothesize that the $1.5^{\circ}$ transducer angle could have been partly compensated by the whitefish swimbladder tilt angle, while the higher perch swimbladder tilt angle has not compensated the transducer angle effect.

The angle shift between nights 1 and 2 was detectable in the fish aspect angles only because lake fish present a low activity at night [14, 23]. For much marine fish, like herring [26], this $1.5^{\circ}$ angle shift and its TS impact will be negligible over their tilt angle variability, even at night [26].

The estimated mean TS were not impacted by the angular misalignment between the two nights. This observation identifies the mean TS as a robust indicator of fish size, as it is not highly sensitive to a small transducer angle mismatch through its average of a set of variable orientations. 
However, there was a biomass mismatch between the two surveys for the two deeper layers due to the mean $S_{A}$ differences. These differences could be attributable to sampling variability between the two nights. Despite previous observations showing a weak impact of the sampling strategy [13], heterogeneity in the spatial fish distribution between the two nights could have occurred. However, from a fisheries management point of view, these differences could be acceptable.

Thus, the angle influence on the calculation of fish biomass is negligible compared to the sampling variability, at least at an error of less than $1.5^{\circ}$.

This study was conducted at $70 \mathrm{kHz}$, but the fish orientation has a growing influence with frequency [33, 8]. It is expected that the impact of the transducer angle on the TS will be higher for higher frequencies (120 or $200 \mathrm{kHz}$ ) and lesser for lower the frequency $(38 \mathrm{kHz})$ [36, 27], as well used for fish stock assessments in lakes.

A default in the transducer horizontality can be empirically assessed on the echograms by scrutinizing the shift between the first and the last ping of deep fish echoes $(>20 \mathrm{~m})$. However, when in the field it is not always easy to obtain a perfect horizontality by moving the transducer. Our study concludes that a small shift in the horizontally $\left(\leq 1.5^{\circ}\right)$ of the transducer has a negligible impact on lake fish stock assessment results. More in situ surveys with different angle defaults and different frequencies should still be done to better assess the impact of transducer angle misalignment on fish stock estimations. 


\section{acknowledgements}

This work was supported by OFB (Office Français de la Biodiversité, previously named Agence Française pour la Biodiversité) and had support from AnaEE France and SOERE OLA (boat and technical facilities). The hydroacoustic and limnological data are issued from OLA, Observatory of LAkes (http://www6.inra.fr/soere-ola CSOERE OLAIS, AnaEE-France, INRAE Thonon-les-Bains, SILA, developed by Eco-Informatics ORE INRAE Team). The authors want to thank Jean-Christophe Hustache and Dr. Helge Balk for their precious help during the survey, as well as Michaël Girard for previous analyses. We want to thank Laurent Berger and the anonymous reviewer for their pertinent comments and remarks about the manuscript. The authors Arthur Blanluet, Jean Guillard and Chloé Goulon are associate members of the Cogitamus Laboratory. 


\section{References}

[1] CEN. Guidance on the estimation of fish abundance with mobile hydroacoustic methods. CSN EN 15910, Comité Européen de Normalisation, Brussels, 2014.

[2] Vladislav Draštík, Malgorzata Godlewska, Helge Balk, Peter Clabburn, Jan Kubečka, Emma Morrissey, Jon Hateley, Ian J. Winfield, Tomáš Mrkvička, and Jean Guillard. Fish hydroacoustic survey standardization: A step forward based on comparisons of methods and systems from vertical surveys of a large deep lake: Fish hydroacoustic survey standardization. Limnology and Oceanography: Methods, 15(10):836-846, 2017.

[3] Anne Mouget, Chloé Goulon, Thomas Axenrot, Helge Balk, Anne LebourgesDhaussy, Malgorzata Godlewska, and Jean Guillard. Including $38 \mathrm{kHz}$ in the standardization protocol for hydroacoustic fish surveys in temperate lakes. Remote Sensing in Ecology and Conservation, 5(4):332-345, December 2019.

[4] Matthias Emmrich, Ian J. Winfield, Jean Guillard, Atle Rustadbakken, Charlotte Vergès, Pietro Volta, Erik Jeppesen, Torben L. Lauridsen, Sandra Brucet, Kerstin Holmgren, Christine Argillier, and Thomas Mehner. Strong correspondence between gillnet catch per unit effort and hydroacoustically derived fish biomass in stratified lakes: Comparison of gillnet catches with fish biomass estimates derived from hydroacoustics. Freshwater Biology, 57(12):2436-2448, December 2012.

[5] Małgorzata Godlewska, Katarzyna Izydorczyk, Zbigniew Kaczkowski, Adam Jóźwik, Bronisław Długoszewski, Shaowen Ye, Yuxi Lian, and Jean Guillard. Do fish and blue-green algae blooms coexist in space and time? Fisheries Research, 173:93-100, January 2016.

[6] Emma Morrissey-McCaffrey, Kieran Rocks, Fiona L. Kelly, and Mary Kelly-Quinn. Effects of differing ground-truth data, transect design and statistical analysis on the repeatability of hydroacoustic assessments of pollan Coregonus autumnalis pollan. Fisheries Management and Ecology, 25(4):304-318, August 2018. 
[7] Jaroslava Frouzova, Jan Kubecka, Helge Balk, and Jan Frouz. Target strength of some European fish species and its dependence on fish body parameters. Fisheries Research, 75(1-3):86-96, September 2005.

[8] J. Michael Jech. Interpretation of multi-frequency acoustic data: Effects of fish orientation. The Journal of the Acoustical Society of America, 129(1):54-63, January 2011.

[9] Michal Tušer, Jan Kubečka, Jaroslava Frouzová, and Oldřich Jarolím. Fish orientation along the longitudinal profile of the Ř́mov reservoir during daytime: Consequences for horizontal acoustic surveys. Fisheries Research, 96(1):23-29, February 2009.

[10] David N. MacLennan, Paul. G. Fernandes, and John Dalen. A consistent approach to definitions and symbols in fisheries acoustics. ICES Journal of Marine Science, 59(2):365-369, April 2002.

[11] Richard H. Love. Dorsal-aspect target strength of an individual fish. The Journal of the Acoustical Society of America, 49(3B):816-823, March 1971.

[12] Frédéric Rimet, Orlane Anneville, Denis Barbet, Cécile Chardon, Laura Crépin, Isabelle Domaizon, Jean-Marcel Dorioz, Laurent Espinat, Victor Frossard, Jean Guillard, Chloé Goulon, Valérie Hamelet, Jean-Christophe Hustache, Stéphan Jacquet, Leslie Lainé, Bernard Montuelle, Pascal Perney, Philippe Quetin, Serena Rasconi, Antoine Schellenberger, Viet Tran-Khac, and Ghislaine Monet. The Observatory on LAkes (OLA) database: Sixty years of environmental data accessible to the public. Journal of Limnology, 79(2):164-178, 2020.

[13] Jean Guillard and Charlotte Vergès. The repeatability of fish biomass and size distribution estimates obtained by hydroacoustic surveys using various sampling strategies and statistical analyses. International Review of Hydrobiology, 92(6):605-617, December 2007. 
[14] Stéphane Masson, Nadine Angeli, Jean Guillard, and Bernadette Pinel-Alloul. Diel vertical and horizontal distribution of crustacean zooplankton and young of the year fish in a sub-alpine lake: an approach based on high frequency sampling. Journal of Plankton Research, 23(10):1041-1060, October 2001.

[15] Jean Guillard, Marie-Elodie Perga, Michel Colon, and Nadine Angeli. Hydroacoustic assessment of young-of-year perch, Perca fluviatilis, population dynamics in an oligotrophic lake (Lake Annecy, France). Fisheries Management and Ecology, 13(5):319327, October 2006.

[16] Benoit Sotton, Orlane Anneville, Sabrina Cadel-Six, Isabelle Domaizon, Sophie Krys, and Jean Guillard. Spatial match between Planktothrix rubescens and whitefish in a mesotrophic peri-alpine lake: Evidence of toxins accumulation. Harmful Algae, 10(6):749-758, September 2011.

[17] Małgorzata Godlewska, Michel Colon, Adam Jóźwik, and Jean Guillard. How pulse lengths impact fish stock estimations during hydroacoustic measurements at $70 \mathrm{kHz}$. Aquatic Living Resources, 24(1):71-78, January 2011.

[18] Kenneth G Foote, Hans Petter Knudsen, and Gudmund Vestnes. Standard calibration of echo sounders and integrators with optimal copper spheres. 1983.

[19] David A. Demer, Laurent Berger, Matteo Bernasconi, Bethke Eckhard, Kevin Boswell, Dezhang Chu, Reka Domokos, Adam Dunford, Sascha Fässler, Stéphane Gauthier, Lawrence T. Hufnagle, J Michael Jech, Naig Le Bouffant, Anne Lebourges Dhaussy, Xavier Lurton, Gavin J. Macaulay, Yannick Perrot, Tim E. Ryan, Sandra Parker-Stetter, Sarah Stienessen, Thomas Weber, and Neal Williamson. Calibration of acoustic instruments. Technical Report 326, ICES, Denmark, May 2015.

[20] Helge Balk and Torfinn Lindem. Sonar4 and Sonar5-Pro post processing systems. Operator manual version 6.01. Technical report, Lindem Data Acquisition, Olso (Norway), 2014. 
[21] Sandra L. Parker-Stetter, Lars G. Rudstam, patrick J. Sullivan, and David M. Warner. Standard operating procedures for fisheries acoustic surveys in the Great Lakes. Special Publication 09-01, Great Lakes Fisheries Commission, 2009.

[22] Victor Frossard, Chloé Goulon, Jean Guillard, Valérie Hamelet, Stéphan Jacquet, Leslie Laine, Fréderic Rimet, and Viet Tran-Khac. Suivi de la qualité des eaux du lac d'Annecy. Rapport 2018. Technical report, SILA (éd.) et INRAE-Thonon, Annecy, 2019.

[23] T. Mehner, S. Busch, I. P. Helland, M. Emmrich, and J. Freyhof. Temperaturerelated nocturnal vertical segregation of coexisting coregonids: Nocturnal segregation of coregonids. Ecology of Freshwater Fish, 19(3):408-419, September 2010.

[24] Daniel L. Yule, Lori M. Evrard, Sébastien Cachera, Michel Colon, and Jean Guillard. Comparing two fish sampling standards over time: largely congruent results but with caveats. Freshwater Biology, 58(10):2074-2088, October 2013.

[25] Kenneth D Carlander. Handbook of Freshwater Fishery Biology, volume 1. Iowa State University Press, Ames, 1969.

[26] Egil Ona. Herring tilt angles, measured through target tracking. In Herring: expectations for a new millenium, pages 461-487, Anchorage, Alaska, 2001. Lowell Wakefield Fisheries Symposia Series.

[27] E. John Simmonds and David N. MacLennan. Fisheries acoustics: theory and practice. Number 10 in Fish and aquatic resources series. Blackwell Science, Oxford ; Ames, Iowa, 2 edition, 2005.

[28] Mathieu Doray, Laurent Berger, Naig Le Bouffant, Jean Yves Coail, Jean Philippe Vacherot, Xavier de La Bernardie, Pierre Morinière, Elisabeth Lys, Romain Schwab, and Pierre Petitgas. A method for controlled target strength measurements of pelagic fish, with application to European anchovy ( Engraulis encrasicolus ). ICES Journal of Marine Science, 73(8):1987-1997, September 2016. 
[29] Richard H. Love. Target strength of an individual fish at any aspect. The Journal of the Acoustical Society of America, 62(6):1397, 1977.

[30] R Core Team. R: A Language and Environment for Statistical Computing. R Foundation for Statistical Computing, Vienna, Austria, 2019.

[31] Victor Frossard, Christine Barbier, Chloé Goulon, Jean Guillard, Valérie Hamelet, Stéphan Jacquet, Leslie Laine, Emilien Lasne, and Fréderic Rimet. Suivi de la qualité des eaux du lac d'Annecy. Rapport 2016. Technical report, SILA (éd.) et INRAE-Thonon, Annecy, 2017.

[32] JHS Blaxter and RS Batty. Swimbladder "behaviour" and target strength. Rapports et Proces-verbaux des Réunions du Conseil International pour l'Exploration de la Mer, 189:233-244, 1990.

[33] Stéphane Gauthier and John K Horne. Acoustic characteristics of forage fish species in the Gulf of Alaska and Bering Sea based on Kirchhoff-approximation models. Canadian Journal of Fisheries and Aquatic Sciences, 61(10):1839-1850, October 2004.

[34] C. Guintard, C. Salaud, Y. Richaudeau, C. Tavernier, H. Desal, R. Bourcier, and B. Chanet. Exploration de l'anatomie de la perche commune Perca fluviatilis (Linnaeus, 1758) [Serraniformes, Percidae]. Cahiers d'Anatomie Comparée, 9:1-20, 2017.

[35] Juha Lilja, Timo J Marjomäki, Juha Jurvelius, Tuomo Rossi, and Erkki Heikkola. Simulation and experimental measurement of side-aspect target strength of Atlantic salmon ( Salmo salar ) at high frequency. Canadian Journal of Fisheries and Aquatic Sciences, 61(11):2227-2236, November 2004.

[36] Odd Nakken and Kjell Olsen. Target strength measurements of fish. Bergen, 1977. Ices. 